\title{
P52 (P. RYLANDS GK. 457) AND THE NOMINA SACRA: Method ANd PRoBABILITY
}

\author{
L.W. Hurtado
}

\begin{abstract}
Summary
This article responds to the recent proposal (by Chris Tuckett) that space considerations suggest that 252 , our earliest NT manuscript, would have written out the name of Jesus in full. This would have implications for the study of the nomina sacra, abbreviations used for divine names (and some other terms) in all our other NT manuscripts. The main emphasis of this article is the importance of taking account of all scribal features of manuscripts in attempting to establish probabilities for lacunae. Careful attention to method and to all the scribal features of 252 suggests that the use of an abbreviated form of the name 'Jesus' is more probable than not, and that 252 is not an early exception to the rule that all NT manuscripts use nomina sacra.
\end{abstract}

\section{Introduction}

Since its identification and publication by a twenty-four year old Colin Roberts in 1935, the famous Rylands fragment of the Gospel of John (P.Rylands Gk. 457, also known as P52, which contains seven partial lines of John 18:31-33 on the recto, and seven more partial lines of 18:37-38 on the verso), has continued to hold an importance incommensurate with its size. ${ }^{1}$ This is largely because it is widely

1 C.H. Roberts, An Unpublished Fragment of the Fourth Gospel in the John Rylands Library (Manchester: MUP, 1935) (hereafter cited as Fragment), reprinted as an article with the same title and with minor changes in BJRL 20 (1936) 45-55 (hereafter, 'Fragment'). Both publications give black and white photographs of the two sides of the fragment. A high-quality slightly oversize colour photograph of the recto can be had from the John Rylands Library as a souvenir postcard, and enlarged digital images can be viewed on the Library's web site: recto: http://rylibweb.man.ac.uk/data1/dg/text/frag2.htm; and verso: http:// rylibweb.man.ac.uk/data1/dg/text/frag3.htm. See also C.H. Roberts, Catalogue of the Greek and Latin Papyri in the John Rylands Library Manchester, Vol. III, Theological and Literary Texts (Manchester: Manchester University Press, 1938) 
regarded as the earliest portion of any NT writing extant, commonly dated to the first half of the second century. ${ }^{2}$ In a recent article, Christopher Tuckett has drawn fresh attention to this fragment, arguing that it likely did not have the distinctive Christian abbreviations called the 'nomina sacra', and claiming that this may have significant ramifications upon widely-held views about this scribal practice. ${ }^{3}$ In what follows, I address these particular questions, indicating why I find Tuckett's analysis unpersuasive. But my more important aim is to stress and illustrate the necessity to pay careful attention to the physical features of manuscripts in attempting to judge probabilities for lacunae.

In the course of preparing this paper, I was made aware of another critique of Tuckett's article written by Charles Hill. Hill kindly sent me a typescript of his article (now published), which I gratefully acknowledge here, and to which I refer in subsequent paragraphs. ${ }^{4} \mathrm{I}$ wish to second Hill's critique and add a few further significant points of my own, emphasizing the importance of method in dealing with lacunae-ridden papyri of which $\$ 252$ is a prime instance. As Tuckett cites a comment of mine about $\mathfrak{P 5 2}$ from another context as consistent with his argument, it may be particularly useful for me to make my own view clear.

\section{Brief Description of $\$ 252$}

But, before I engage Tuckett's argument and the larger issues of method that it raises, some further introductory information about

1-3. There is also now a photo-plate of $\mathfrak{P} 52$ in W.J. Elliott \& D.C. Parker (eds.), The New Testament in Greek IV, The Gospel according to St. John: Volume One, the Papyri (NTTS 20; Leiden: Brill, 1995), which is now the most recent transcription/edition of the text as well.

2 Cf. Andreas Schmidt, 'Zwei Anmerkungen zu P. Ryl. III 457', APF 35 (1989) 11-12, who proposed a date of $170 \mathrm{CE}+/-25$. See also $\mathrm{n}$. 20 below. Schmidt also suggested that $\$ 52$ was a 'Mischtext' combining John 18:31 and 19:7 in the recto, which I do not find persuasive.

3 C.M. Tuckett, ' $\$ 52$ and Nomina Sacra', NTS 47 (2001) 544-48. See especially p. 548, where he proposes that his may have 'repercussions for any broader study of the nomina sacra', and may 'cast some doubt on how regular the practice...in early Christianity really was'. On the scribal convention involved, see esp. C.H. Roberts, 'Nomina Sacra: Origins and Significance', in Manuscript, Society and Belief in Early Christian Egypt (Schwiech Lectures, 1977; London: OUP, 1979) 26-48; and L.W. Hurtado, 'The Origin of the Nomina Sacra: A Proposal', JBL 117 (1998) 655-73.

4 Charles E. Hill, 'Did the Scribe of $\$ 52$ Use the Nomina Sacra? Another Look', NTS 48 (2002) 587-92. 
P52 may be helpful. 5 What survives is an upper part of a single leaf of a papyrus codex estimated to have comprised ca. 130 pages (66 leaves, i.e., 33 folded sheets) and that probably contained solely the Gospel of John. The fragment itself measures $8.9 \times 6 \mathrm{~cm}$, the original full page likely measuring $c a .21 \times 20 \mathrm{~cm}$. As mentioned already, parts of seven lines survive on the recto and the verso, along with part of the inner margin and nearly all of the top margin of the extant portion of the leaf. Assuming that the manuscript contained pretty much what we know as the text of the Gospel of John (though it is widely thought that $\$ 52$ has a variant not otherwise attested), we can estimate pages of eighteen lines each, with lines estimated to vary between 28 and 35 characters each, the recto lines likely averaging slightly more characters than the verso lines. ${ }^{6}$ The margins all appear to have been very generous (e.g., the top margin was well over $2 \mathrm{~cm}$ ); and the characters range from ca. 0.3 to $0.4 \mathrm{~cm}$ high, with spacing between the lines about $0.5 \mathrm{~cm}$. As Roberts commented, 'to judge from the spacing and the size of the hand, it is unlikely that the format was affected by considerations of economy'.7

So far as we are able to ascertain, the scribe appears not to have used punctuation or breathing marks; but we can see instances of the diaeresis over an initial iota (probably in recto line 1, and certainly in recto line 2 and verso line 2). The orthography as well as the layout reflect an effort to produce a readable copy, with clearly-formed letters; but the scribe's effort falls noticeably short of the skills of the best book hands of the day. ${ }^{8}$ This is probably what Roberts meant in

\footnotetext{
5 I cite here the description and measurements given by Roberts in his 1936 article, 'Fragment', which differ slightly from his description in his 1935 book, Fragment. See also Joseph van Haelst, Catalogue des papyrus littéraires juifs et chrétiens (Paris: Sorbonne, 1976), 167-68 (\#462); but van Haelst appears to rely on measurements given in Roberts' 1935 publication. For initial orientation to the study of papyri and Greek palaeography, see esp. E.G. Turner, Greek Manuscripts of the Ancient World ( $2^{\text {nd }}$ ed. revised and enlarged, ed. P.J. Parsons; London: Institute of Classical Studies, 1987); C.H. Roberts, Greek Literary Hands (Oxford: Clarendon, 1955); B.M. Metzger, Manuscripts of the Greek Bible: An Introduction to Palaeography (New York/Oxford: OUP, 1981).

6 Roberts' proposal has been commonly accepted that in the verso line 2 the

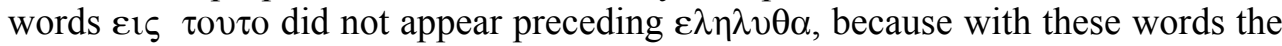
line contain an estimated 38 letters, considerably longer than any of the estimates for the other verso lines $(29,30,28,31,28,31)$. See Roberts, 'Fragment', 55, and Fragment, 25, 29. I do not judge this to be a conclusive argument, but it is certainly plausible.

7 Roberts, 'Fragment', 52.

8 Cf., e.g., the second-century copy of the Iliad, Bodl. MS. Gr. Class. a. I (P) shown in Turner, Greek Manuscripts of the Ancient World, 39.
} 
writing that the copyist of $\$ 52$ was probably not 'a practised scribe'. Roberts judged the description of the hand of P.Egerton 2 as applicable also to $\$ 52$ : 'a somewhat "informal air" about it and with no claims to fine writing', nevertheless, 'a careful piece of work'. 9 More specifically, P52 exhibits a 'heavy, rounded and rather elaborate hand', a certain irregularity and clumsiness in forming some letters (e.g., the etas, and cf. the two alphas in recto line 2), and a fondness for small flourishes or hooks on the end of strokes (e.g., the upsilons, iotas, and the first alpha in recto line 2). 10 The importance of taking adequate account of all these and other scribal features will become apparent later in this paper.

\section{P52 and the Nomina Sacra}

To turn now to the precise question before us, I should make two preliminary things clear at the outset. First, there is in fact not nearly as much at stake in the question as Tuckett suggests. He proposes that the absence of nomina sacra forms in $\$ 52$ could indicate that the scribal practice either did not emerge as early, or did not become as widespread, as some (such as yours truly) have contended.11 But, even if $\$ 52$ did not contain nomina sacra forms, the basic conclusion represented in scholarly discussions of the data remains secure: Whatever its derivation (whether from Jewish scribal precedents or originating in Christian circles), the scribal practice emerged very early and quickly became amazingly pervasive in Christian usage; and, together with the equally clear preference for the codex, the nomina sacra comprise what I have elsewhere referred to as the earliest evidence of an emergent material and visual culture in ancient Christianity. ${ }^{12}$ It would take much more than the demonstrative absence of nomina sacra forms in $\$ 52$ to change that conclusion.

There are a few Christian manuscripts without the nomina sacra, and we should not be surprised at this. Given that there was no

9 Roberts, 'Fragment', 48.

10 I paraphrase from Roberts, 'Fragment', 46, and also draw upon my own examination of the fragment.

11 Tuckett, ' $\$ 52$ ', 548. Cf., e.g., Hurtado, 'Origin of the Nomina Sacra'.

12 Larry W. Hurtado, 'The Earliest Evidence of an Emerging Christian Material and Visual Culture: The Codex, the Nomina Sacra and the Staurogram', in Text and Artifact in the Religions of Mediterranean Antiquity: Essays in Honour of Peter Richardson, eds. S.G. Wilson \& M. Desjardins (Waterloo, Ontario: Wilfrid Laurier University Press, 2000) 271-88. Supporting Roberts, I have proposed that the origin of the nomina sacra practice probably lies sometime in the late first century, and certainly not much later than 100 CE (Hurtado, 'The Origin of the Nomina Sacra'). 
legislative mechanism for enforcing the scribal practice in question across the geographical expanse of Christian circles of the second and third centuries, we should not expect the nomina sacra to have been employed in uniform fashion or by all Christian scribes. ${ }^{13}$ Tuckett warns against an a priori assumption that every early Christian manuscript used nomina sacra forms; but his warning is unnecessary, for I know of no one conversant with the data and sound historical method who has urged such an assumption. ${ }^{14}$ Based on the many verifiable cases and the comparative paucity of exceptions, however, where we cannot verify things empirically it is more probable that an early Christian manuscript did contain nomina sacra forms of relevant words (especially the four words for 'Jesus', 'God', 'Lord', and 'Christ') than the alternative. I shall return to this point later.

My point here is that it is not particularly remarkable that there are a few examples of Christian manuscripts without the nomina sacra. The wonder is that there are so few, and that the nomina sacra are so well attested and so early. So far as I know, among the 300 or so indisputably Christian manuscripts from before $300 \mathrm{CE}$, those that demonstrably did not have any nomina sacra forms can be counted on the fingers of our two hands. ${ }^{15}$ So, I repeat that the early emergence and impressively wide adoption of the scribal convention remains assured, whatever may be the case with $\$ 52$.

My second preliminary point is that any claim about how the scribe of $\$ 252$ handled the words commonly abbreviated as nomina sacra can only amount to scholarly guesswork. Unfortunately, in the

13 I emphasize that the variety of ways in which the nomina sacra forms were written (esp. true in the case of I $\eta \sigma 0 v \varsigma$ ) does not work against this conclusion. All the variations in the ways that these words were abbreviated reflect a shared concern to mark them off visually from the rest of the text, and thus probably represent expressions of a shared scribal piety.

14 Tuckett, ' $\$ 52$ ', 656. An a priori assumption would be deduced from some general principle of supposedly self-evident reasoning and formed prior to examining the relevant data. The judgements of palaeographers and those scholars who learn from their work, however, are inductively developed from extant data. Making an inference or judging probabilities based on extant data is different from making an a priori statement.

15 Roberts described exceptions known to him as three prayer texts, three magical texts, and two amulets, and a 'medical miscellany written for private use' (Manuscript, 37-39). Tuckett ('P52', 546 n. 11) cites P. Oxy. 407 (erroneously given by Tuckett as P. Oxy. 405), a 'prayer text,' as having no abbreviated forms

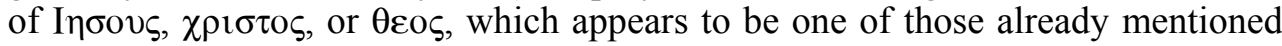
by Roberts. It is worth noting that all of these manuscripts are copies of texts that do not form part of the emergent canon of Old Testament or New Testament. So, an actual instance of a copy of such a text in which unabbreviated forms of these key words were used would be a notable exception. 
portions of lines of the Gospel of John preserved in $\$ 252$, there is no surviving instance of any of the words commonly treated as nomina sacra by early Christian scribes. If, however, the full text of John $18: 31-33,37-38$ originally contained on the two complete sides of this codex leaf corresponded basically with what we know as the wording of these verses, then the name 'Inбovऽ' would have appeared in the missing part of lines 2 and 5 of the recto side. This is the only one of the relevant words that may have appeared in these verses. But was it written out, or was it written in one of the abbreviated forms so well attested in early Christian manuscripts? The answer can only be an educated guess, so the better our familiarity with all the relevant data the better our guess.

Tuckett argues that Inoovs was probably not abbreviated, contending that any abbreviated form would have produced short lines with too few letters in comparison with the estimated number of letters in the other recto lines. It is important to reiterate that Tuckett's whole case rests upon small differences in estimates of the number of characters in the lines of $\$ 52.16$ But there are three problems with the argument that render it unpersuasive: (1) insufficiently-considered variations in spelling of certain words that would noticeably reduce the differences in estimated numbers of characters, (2) more seriously, an inadequate analysis of the scribal features of $\$ 252$, and (3) a methodological peculiarity in handling the unavoidably inferential task imposed when dealing with lacunose manuscripts.

As Tuckett points out, the suggestion that $\$ 25$ probably did not exhibit any of the nomina sacra forms of Inбov Roberts; and it rested essentially on the same basis: A nomina sacra form of Inoovs in lines 2 and 5 of the recto would produce lines with character counts somewhat smaller than most or all of the estimated character-counts for the other extant lines of the recto. ${ }^{17}$ Tuckett notes with some puzzlement, however, that in subsequent discussions of the nomina sacra, most fully in his 1977 Schweich Lectures, Roberts seems to have ignored or backed away from this initial judgment about $\mathfrak{P} 52 .{ }^{18}$ I submit that Roberts' shift in view is not really so

\footnotetext{
16 Tuckett grants Roberts' caution about resting much on estimates of linelengths, but complains 'there is unfortunately little else to go on!' (457, n. 17, citing Roberts, Fragment, 18-19). As I shall show, this is precisely Tuckett's key mistake.

17 Roberts, Fragment, 17-19; id., 'Fragment', 48-49.

18 Roberts, 'Nomina Sacra', esp. 28, and also 38, where he states that 'there is no certain instance of the name [I
} 
puzzling, and that it is worth exploring briefly here the factors involved.

In the 1930s, when Roberts published P52, it was still widely thought that the nomina sacra probably appeared no earlier than sometime in the second century (though that view was soon to change). In another publication of about the same period, for example, Roberts wrote of the nomina sacra that it looks as though the practice, whatever its origin, only became general in the course of the second century A.D.'. ${ }^{19}$ Now, if one reads carefully Roberts' discussion in his 1935 and 1936 publications on P52, it also becomes clear that he was concerned to date this manuscript to the early second century, and that he offered the alleged absence of nomina sacra forms in support of this early dating. ${ }^{20}$

Indeed, it is evident that Roberts was specifically concerned to date P52 in competition with the then recently-published P. Egerton 2, fragments of an 'Unknown Gospel', whose editors had dated it to the mid-second century $\mathrm{CE}$. In several other respects, the two manuscripts were comparable, but Roberts saw the possible absence of nomina sacra in $\$ 52$ as justifying a very early date for it, even allowing him to date it slightly earlier still than P. Egerton 2, which does have numerous nomina sacra forms. ${ }^{21}$

appears to mean written out in full] in any text of the New Testament or indeed in any book as distinct from occasional and private papers'.

19 Roberts, Catalogue (see note 1), 7.

20 Roberts granted that the presence of nomina sacra forms would not count as decisive evidence against a second-century date (citing P. Egerton 2 as an instance), nevertheless, he argued that the alleged absence of nomina sacra forms in $\$ 52$ 'would make it more difficult to assign a late date' to the manuscript ('Fragment', 49). However, in light of the more recently published Köln fragment (P. Köln VI 255), which appears to be part of the same manuscript as the P. Egerton 2, its date may have to be adjusted downward to ca. 200 CE. See Michael Gronewald, 'Unbekanntes Evangelium oder Evangelienharmonie (Fragment aus dem 'Evangelium Egerton")', in Kölner Papyri (P. Köln), Vol. VI, (Cologne: Rheinisch-Westfälischen Akademischer Wissenschaften unter Universität Köln, 1987) 136-45. In a letter to me dated 02 January 2003, J.D. Thomas indicated that he too 'should certainly want to date the papyrus c. AD 200, not earlier'. As the dating of $\$ 252$ has been linked with the putative date of the Egerton manuscript, re-mooring the latter downstream chronologically may well mean that $\$ 52$ should be moved a bit later as well.

21 H.I. Bell \& T.C. Skeat, Fragments of an Unknown Gospel and Other Early Christian Papyri (London: Trustees of the British Museaum, 1935) 2, where their palaeographical analysis led them to judge a date later than the mid-second century 'extremely improbable', and pp. 2-4 for description of nomina sacra forms of several words in P. Egerton 2. Bell \& Skeat expressed some surprise that P. Egerton 2 showed the nomina sacra 'so well established by the middle of the second century' (p. 2). But, in light of other then-recent evidence such as the 
In the decades subsequent to his publication of $\$ 552$, however, Roberts (along with most other palaeographers) came to the view that the nomina sacra probably emerged much earlier than thought previously, and that the practice was already a pervasive Christian scribal convention by the early second century. ${ }^{22}$ As Christian papyri continued to be made available for study, the pervasiveness and early origin of the nomina sacra became undeniable. By his 1977 Schweich Lectures, Roberts confidently opined that the convention probably began with the name Inoovs, and that it must have its origins at least as early as $100 \mathrm{CE} .^{23}$ In short, it no longer could support his proposed dating of $\$ 52$ to suggest that the manuscript did not have Inoovs written as a nomen sacrum; and his increased familiarity with the papyrological evidence seems to have led him to the view that this was in any case improbable.

Tuckett, however, endeavors to reassert Roberts' initial proposal from 1935. But Tuckett's argument is only an expanded statement of Roberts' 1935 surmise that the presence of any nomina sacra form of Inoovs in $\mathfrak{P} 52$ is unlikely, as it would involve lines significantly shorter than the probable length of adjacent lines. Tuckett writes that 'any judgement must be based on the lengths of the lines and the number of letters in each line' (emphasis mine). ${ }^{24}$ The first points I wish to make, therefore, concern the counting of letters; and I echo here points made by Hill.

\section{The Letter-Counts}

If Jesus' name was written as a two-character abbreviation, the following character-counts for lines $1-6$ of the recto can be estimated: $35,31,31,34,28$, and 31 . Tuckett's sole point is that recto line 2 and

Chester Beatty manuscripts (esp. P. Beatty VI, of Numbers and Deuteronomy, and also dated to the mid-second century), they saw the presence of nomina sacra in the Egerton manuscript as 'no argument whatever against an early date' (p. 4). Indeed, they noted that the nomina sacra forms in P. Egerton 2 include the

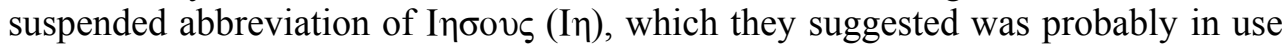
'from the Apostolic age downwards', and 'may actually have been the first to be adopted' (p. 3).

22 Among other important evidence that helped to form the view about the early spread of the convention, there was the Chester Beatty manuscript of Numbers and Deuteronomy (P. Beatty VI), dated by Kenyon to the early second century. For discussion of its date and the nomina sacra forms, see F.G. Kenyon, The Chester Beatty Biblical Papyri: Descriptions and Texts of the Twelve Manuscripts on Papyrus of the Greek Bible, Fasciculus V, Numbers and Deuteronomy (London: Emery Walker, 1935) ix-x.

23 Roberts, Manuscript, 37.

24 Tuckett, 'P52', 546. 
(especially) line 5 would have a somewhat smaller number of letters in comparison with these other lines. ${ }^{25} \mathrm{He}$ urges that if Inoovs was written out fully (Inoov in line 2, and Inoovv in line 5), however, the letter-counts for recto lines $1-6$ would be $35,34,31,34,32,31.26$ In short, the full spelling of Inoovs in lines 2 and 5 would reduce the disparity in the estimated number of letters between these and the other recto lines.

In response, I begin with an observation made also by Hill. Although Tuckett acknowledges other possibilities in his footnotes, he rather consistently bases his argument on the assumption that any nomina sacra spelling of Inoovs would have been a two-character abbreviation, either the suspended form, IH, or the contracted form, the iota and the final letter of the inflected forms (e.g., I $\Sigma$ ). But Hill rightly emphasizes that the three-character form of Jesus' name, e.g., $\mathrm{IH} \Sigma$, is also sufficiently well attested, even in Christian manuscripts dated to the second and third centuries, that it is probably as likely in P52 in lines 2 and 5 of the recto. ${ }^{27}$ If we re-calculate on this assumption, then the estimated number of letters in recto line 2 would be 32 (cf. Tuckett's count of 31 ), and 29 (not 28) in recto line 5. Further, if the scribe of $\$ 52$ wrote $\varepsilon \phi \omega v \eta \sigma \varepsilon v$ (i.e., with the final $n u$ ) in recto line 5, which Hill shows to be entirely plausible, then this line would amount to 30 characters (or 29 characters if Inoovs were written in a two-character abbreviation) 28

25 Line 5 would be seven letters shorter than line 1 ; but line 1 is more unusually long than is line 5 unusually short.

26 Tuckett (' $\$ 52$ ', 548) gives the numbers as $35,33,31,34,31,31$. But, as Hill notes ('Scribe,' $1-2$, nn. 2-3), the numbers for lines 2 and 5 are incorrect. For his study, Tuckett adopts the reconstruction of $\$ 252$ given by Elliott \& Parker, The New Testament in Greek IV, 72.

27 Hill, 'Scribe', 587-89. Hill points to the following pre-fourth-century papyri manuscripts containing the Gospel of John: P. Oxy. 208+1781 (P5, $3^{\text {rd }}$ cent.), P. Oxy. 1228 (P22, $3^{\text {rd }}$ cent.), P. Oxy. 1780 (P39, early $3^{\text {rd }}$ cent.), P. Oxy 3523 (\$90, $2^{\text {nd }}$ cent.), P. Oxy 4445 (P106, $3^{\text {rd }}$ cent.), P. Oxy. 4447 (P108, $3^{\text {rd }}$ cent.). From the same basic period, $\mathfrak{P} 28\left(3^{\text {rd }} / 4^{\text {th }}\right.$ cent.), $\mathfrak{P} 75$ (late $2^{\text {nd }} /$ early $3^{\text {rd }}$ cent. $)$, and P66 (early/mid $-3^{\text {rd }}$ cent) have the two-character contracted forms, and $\$ 45$ (early $3^{\text {rd }}$ cent.) and P. Egerton 2 have the two-character suspended form. $\$ 75$ and $\$ 45$ also have the three-character forms. Hill refers to these three-character forms as 'long contracted', whereas Roberts called them 'conflated' forms; but I would suggest that Bell \& Skeat may have been correct to refer to them as 'IH with the case-endings added' (Bell \& Skeat, Fragments, 3). I would propose 'long suspended' as a designation of these forms.

28 Hill, 'Scribe', 589. He notes that the final $n u$ appears here in a number of mss ( $\aleph, \mathrm{A}, \mathrm{C}, \mathrm{W}, \mathrm{D}, \mathrm{L} . \mathrm{N}, \Delta, \Psi, 33,124,579,1071$ ), and that $\varepsilon \xi \eta \lambda \theta \varepsilon v$ (followed by $\pi \alpha \lambda \iota v)$ appears in $\$ 66$ and $\$ 90$. Also, we must suppose with most who have considered the matter that in recto 1. 5 Pilate's name was spelled $\pi \varepsilon \imath \lambda \alpha \tau o \varsigma$ (accepted as likely also by Tuckett, 'P52', 547). 
Given that Tuckett's sole point has to do with estimated lettercounts, these are telling criticisms. With a three-letter form of Inбovs in recto 2 and 5, and with $\varepsilon \phi \omega v \eta \sigma \varepsilon v$ in recto 5, lines 1-6 would run $35,32,31,34,30,31$. The spread between the lines with fewest and most letters would be five (30-35), not seven (28-35) as in Tuckett's calculation. Moreover, recto 2 would be fully within the span of estimated letter-counts of other extant lines, and recto 5 would be only one letter shorter than the next two shortest lines. Even with a two-character abbreviation of Inoovs, recto line 2 would have 31 letters, and line 5 would have 29 , the latter only two letters shorter than lines 3 and 6 . In light of the estimated numbers of letters in the four undisputed lines of the recto and the seven lines of the verso (29, $30,30,28,31,28,31),{ }^{29}$ should we expect more uniformity for this scribe?

\section{Observing Scribal Data}

This question leads me to my next (and larger) point about method, which is that arguments based on estimated numbers of letters per line are almost meaningless unless we take account of the scribal hand of the manuscript in question. In a note where Tuckett mentions and discards the possible variations in spelling that would require him to alter his preferred letter-counts, he cites Roberts' caution about laying too much on estimating the number of letters, but then exclaims that 'there is unfortunately little else to go on!' 30 But we are not so unfortunate as that, and there is in fact significantly more to do than simple estimates of letter numbers.

More specifically, any use of estimated numbers of letters is only as good as the demonstrable regularity of a given scribe's practice. That is, if a particular scribe exhibits a fairly strict regularity in size and spacing of letters and words, then we can feel somewhat more confident in offering arguments based on estimates of the number of characters in lines. Even in such a case, however, it is easy to demonstrate the danger of expecting too much regularity in the

29 I base these counts on the reconstructed text given by Roberts ('Fragment', 54). Tuckett's letter-counts for the verso apply to lines 2-7, because he used the text as printed in Elliott \& Parker (72), which does not give a reconstruction for what is obviously the initial part of verso line 1 ; and in line 7 has a square bracket indicating a lacunae following the extant letters $\varepsilon \mu \mathrm{l}$, but no reconstruction for it. Tuckett is, therefore, not quite correct to say that the reconstructions by Roberts and by Elliott \& Parker 'agree almost exactly' ('P52', 546 n. 13).

30 Tuckett, 'P52', 547, n. 17. 
number of characters per line. ${ }^{31}$ But, if a scribe manifests significant variation in orthographic practice, then arguments based on precisely estimated numbers of letters in lacunose lines are even more dubious, and, indeed, may well be devoid of probative value. So, in terms of right method, we should first try to establish the scribe's 'm.o.' before we attempt very precise estimates of letter-counts, and certainly before we make much depend upon small differences in such estimates. This is essentially where Tuckett made his operational mistake. ${ }^{32}$ So, let us return to making observations about the scribal hand of $\$ 52$.

As noted already, the scribe was certainly aiming at careful, clear presentation of the text being copied. In particular, the generous margins and line-spacing, the use of diaeresis over initial iotas, and the general care with which the letters are formed all indicate a desire to produce an easily-readable manuscript. Clearly, the scribe was not capable of a formal book-hand style (e.g., the very imperfectly bilinear writing), but nevertheless clearly did his or her best to produce an easy-to-use copy. ${ }^{33}$

But, equally clearly, and very importantly for arguments based on letter-counting, the scribe's ability did not extend to a very tight

31 In commenting on an earlier draft of this essay, Peter Head illustrated this point with reference to $\$ 75$. The scribe of $\$ 75$ executed a much more consistent hand in shapes and sizes of letters, and also clearly aimed for both left-hand and right-hand justification of lines. Yet there are variations in the number of characters per line fully equal to the estimated differences in lines of the recto of $\$ 52$ if a two-letter

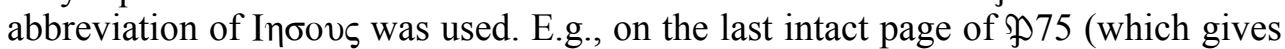
John 9:40b-10:14), line-counts for the first twenty lines are as follows (the smallest and largest line-counts given in boldface): $29,28,27, \mathbf{2 4}, \mathbf{3 1}, 27, \mathbf{3 1}, 29$, $25,29,28,29,27,29,25,27,29, \mathbf{2 4}, 28,26$. The difference between highest and lowest line-counts is seven characters. See V. Martin \& R. Kasser, Papyrus Bodmer XV: Évangile de Jean chap. 1-15 (Cologny-Geneva: Bibliotheca Bodmeriana, 1961), plate 88, text printed on p. 60 .

32 As I have mentioned already, in a footnote to his article Tuckett cites a brief comment of mine about the 'considerable care' exhibited by the scribe of $\$ 52$, and he then states that 'a greater rather than a lesser regularity in the line lengths would sit with this observation well' (Tuckett, 'P52', 548 n. 20). Lest any readers misunderstand Tuckett's note, I explain that the private communication to which he refers was a brief conversation in which I conveyed a general impression based on my own first opportunity to examine $\mathfrak{P} 52$ in a 1999 visit to the Rylands Library. The question of whether $\$ 52$ contained nomina sacra forms did not come up in the conversation. I did not comment on his article or the argument presented in it, which I did not know of until its publication.

33 I advisedly allow for either gender of the scribe, for, as Kim Haines-Eitzen has shown, there is some evidence of female as well as male scribes: Guardians of Letters: Literacy, Power, and the Transmitters of Early Christian Literature (Oxford/New York: Oxford University Press, 2000), esp. 41-52. 
regularity in the size or spacing of letters. This is immediately apparent by comparing the first two lines of the recto. In the initial 2.5 $\mathrm{cm}$ of line 2 the scribe wrote the six letters of ov $\delta \varepsilon v \alpha$; but in the equivalent space of line 1 we have the eight letters otrov $\alpha \alpha$. The letters in these two lines are obviously spaced differently, and are even of slightly different sizes (cf. the alphas in lines 1 and 2). Likewise, compare sizes and shapes of the alphas in verso lines 2-4, or the larger size of the sigma of recto line 4 with the smaller sigma in verso line 3.

Further, as Hill noted, we can see somewhat greater spacing before the initial iotas of $10 v \delta \alpha \mathrm{r}[\mathrm{ol}]$ in recto line 1 and of the $\mathrm{tv} \alpha$ in verso line 2 , and also before and after the initial iota of the $\mathrm{tv \alpha}$ in recto line 2.34 There is also a wider space between the $n u$ of $[\varepsilon \imath] \pi \varepsilon v$ and the initial sigma of $\sigma \eta \mu \alpha \mathrm{v} \omega[\mathrm{v}]$ in recto line 3. Moreover, although the lacuna before $\eta \mu \varepsilon[\mathrm{lv}]$ in recto line 1 makes it difficult to be certain, I propose that there is a similarly wider space between this word and the preceding $10 v \delta \alpha \imath[\mathrm{ol}] .35$

Still further, when Christian scribes used nomina sacra forms, they often have somewhat larger spaces before and after the forms (a point made by Hill as well). ${ }^{36}$ Of course, we cannot test the scribe of $\$ 52$

34 Roberts ('Fragment', 55) was uncertain whether what could be a diaeresis above the iota of rovodior in recto line 1 was that or the remainder of iota that extended above the line here. I judge the mark in question to be the remnant of a dieresis (a view supported by J.D. Thomas in comments on an earlier draft of this essay). It is printed with a diaeresis in Elliott \& Parker, The New Testament in Greek IV.

35 Cf. Roberts ('Fragment', 55) who apparently had this point in the line in view in judging that the scribe of $\$ 252$ 'did not adopt the common practice . . . of indicating either the beginning or the end of a speech by leaving a small blank space...' I make no claim for the scribe being regular in the use of such spaces, but careful examination leads me to think that we do have an extra-wide space at such a point in recto line 1 before the $\eta \mu \varepsilon v v$. In his slightly later publication of P. Rylands Grk. 458 (a second-century BCE fragment of Deuteronomy), Roberts noted the curious spaces at the end of a sentence, a clause or a group of words, and he granted that some similar practice might have been operative in $\$ 252$, although 'it is far less clearly marked in this text and probably the scribe only employed it at the end of clauses' ('Two Biblical Papyri in the John Rylands Library Manchester', BJRL 20 [1936] 226-27 [219-36]). But even the occasional use of such spaces at the end of clauses or groups of words would make it dubious to expect a regular number of characters in each line. The use of such spaces probably derives from Jewish scribal practice, as described now by Emanuel Tov, 'Scribal Features of Early Witnesses of Greek Scripture', in The Old Greek Psalter: Studies in Honour of Albert Pietersma, eds. R.J.V. Hiebert, C.E. Cox \& P.J. Gentry (Sheffield: Sheffield Academic Press, 2001) 125-48.

36 Hill, 'Scribe', 589, cites several examples of this in P. Egerton 2, which is regarded as the closest comparison to the scribal hand of $\$ 52$. 
on this particular matter. But if the scribe did use nomina sacra forms it is entirely likely that he also allowed such larger spaces before and after them. This would further complicate judgments based simply on counting the number of characters in lines. In short, a smaller number of characters in one line could easily take up the same amount of space as a larger number in another line.

In sum of these observations, the scribe of $\$ 252$ was not sufficiently regular in his formation or spacing of letters to lead us to expect a close similarity in the numbers of letters in the lines of the text. It is, therefore, very dubious indeed to make claims about whether $\$ 252$ contained an abbreviated form of Inoov on whether it would produce lines from one to three letters fewer than estimates of the next shortest lines (lines 3 and 6). ${ }^{37}$

\section{On Probabilities}

My final point is also to do with method. In cases where the historical data are beset with lacunae, surely the right procedure is to reason from the known to the unknown in making inferences about the lacunae. Given the clear evidence of a pervasive preference for nomina sacra forms by Christian scribes of the second century and thereafter, wherever we can verify matters, especially a preference for one of the abbreviated forms for Inoovs, I submit that sound method requires us to take it as more probable that the scribe of $\$ 52$ observed this convention as well than that he or she did not, unless we have strong reason to think otherwise. In the preceding discussion, I trust that I have shown that we do not have a sufficiently strong basis for thinking that $\$ 252$ is one of the very few exceptions to this Christian scribal practice.

Empirically speaking, of course, it remains unverified whether P52 exhibited nomina sacra. $\$ 52$ cannot count against the widelyendorsed judgment that the practice began early and spread quickly; and it cannot count as evidence in support of that judgment. But if we wish to use all the relevant evidence to establish a probability for P52, it is a safer bet that the scribe of this manuscript did write Inoovs as a nomen sacrum. 38

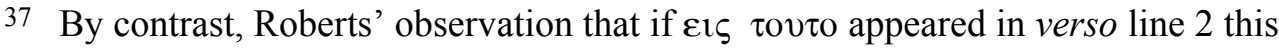
would produce a line estimated to have had 38 letters, seven letters longer than the next longest verso line estimate (31, in lines 5 and 7) has been accepted widely, and is more plausible.

38 In a letter to me dated 10 January 2003 giving comments on an earlier draft of this article, T.C. Skeat described his own attempt to address the question posed in Tuckett's article by first measuring widths of the scribe's individual Greek 


\section{Conclusion}

Whether $\$ 52$ did or did not have some nomina sacra form of Inбovs is a relatively small matter that can be addressed only on the basis of the sort of highly detailed observations that I have urged here. The larger concern that I underscore here is the importance of following an adequate method in dealing with such questions. My fundamental point is that sound method requires a rather thorough acquaintance with the scribal features of early Christian manuscripts in general, and particular attention to all the scribal features of any manuscript about which we seek to judge probabilities. ${ }^{39}$

characters to see what might fit in the lacunose lines in question. He concluded that both the fully-spelled and abbreviated forms of Inoovs 'would be equally possible' (emphasis his). And he went on to propose that this as significant 'because if there is a choice, the overwhelming probability is that nomina sacra were used in P52' (emphasis his). So, Elliott \& Parker are probably correct after all in reconstructing the lacunose lines of $\$ 52$ with Inoovs written as a nomen sacrum, although whether it was a two-letter or three-letter form is somewhat more difficult to posit with confidence.

39 I thank Charles Hill, David Parker, Peter Head, J.D. Thomas, and T.C. Skeat for comments and observations on earlier drafts of this essay. 